\title{
Improving access to IT services for people with disability through software aids
}

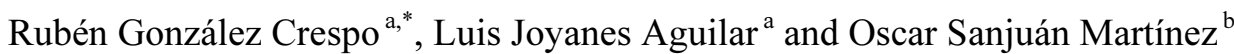 \\ ${ }^{a}$ Department of Computer Science, Pontifical University of Salamanca, Madrid, Spain \\ ${ }^{\mathrm{b}}$ Department of Computer Science, Carlos III University, Madrid, Spain
}

Keywords: Accessibility, usability, non-restricted HCI, disabilities, deafness

On November 24, 2008, Rubén González Crespo defended his $\mathrm{PhD}$ thesis at Pontifical University of Salamanca, titled: "Middleware architectures to adapt online contents for achieving success in changing environments using emerging techniques". The research was funded by the Pablo VI Foundation. Rubén González Crespo defended his dissertation in a publicly open presentation held in the College of Engineering ad Architecture at the Pontifical University of Salamanca, Madrid campus, and was able to comment on every question raised by his thesis committee and the audience. The thesis was supervised by his advisors, Luis Joyanes Aguilar and Oscar Sanjuán Martínez, and the rest of his thesis committee, Mateo Valero Cortés, Juan Manuel Cueva Lovelle, Vidal Alonso Secades, Javier Bustamante Donas and Alfonso López Rivero. The thesis has been read and approved by his thesis committee, receiving the highest rating. All of them were present at the presentation.

\section{Thesis summary}

This thesis purposes a way along which emerging design and programming techniques can be used for conversion and construction of accessible web sites. Accessibility, in web application environment, is present in different laws in multiple countries, and has to be addressed so that all people, regardless of their condition and nationality, can communicate and use technology without any sort of impediment.

This principle is challenged when dealing with people severely handicapped, with whom currently existing difficulties can turn using web sites as gateways to the information society into something almost impossible. People with pre-locutive hearing incapacity, that is, people who have never been able to hear nor talk, constitute an example. The complexity of learning a language, its writing and the expressions commonly used by non-handicapped people, constitute a mayor entry barrier for them. This work proposes a solution based in adapting sign-scripting, a mechanism for graphic representation of sign language, to the environment of the information society [1].

Besides this problem, we are facing a second one of an equal or even greater magnitude. Public Administration websites must be accessible on an AA level, and this shall apply also to websites belonging to mayor companies providing services of general interest and to all those entities and companies that receive public financing, including educational institutions, training centers and universities, as well as private centers receiving public finance. Would it then be possible to mitigate the costs of this transformation?, or, on the contrary, is it necessary to go through a full re-design process for these websites,

*Corresponding author. E-mail: ruben.gonzalez@upsam.es. 


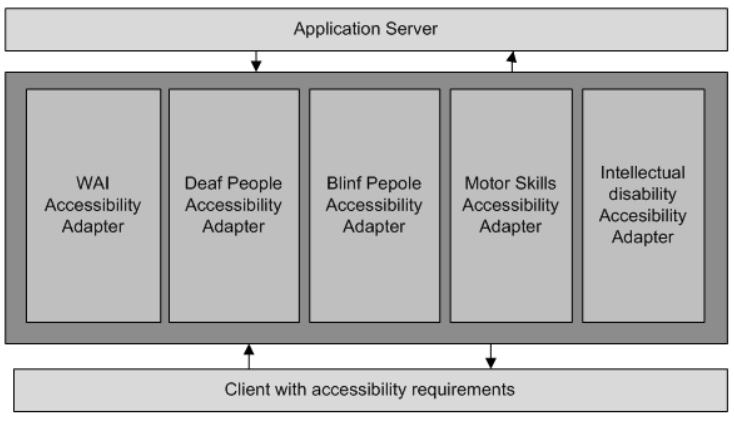

Fig. 1. Architecture overview.

with the high cost this implies [2]. We must not forget either that the spanish PYMES, which represents a high percentage of the spanish companies, will be joining those previously mentioned.

In order to solve these problems a platform which includes a complete solution to accessibility is considered. In this thesis there is an implementation to this global platform, composed by two architectures. Each one of them is oriented to solve separately, but in a collaborative manner when required, depending on the kind of user, the problems exposed on previous paragraphs, being able to obtain web applications accessible with AA level for people with severe hearing incapacity through "Sign Writing".

In order to solve these problems a platform which includes a complete solution to accessibility is considered (Fig. 1). In this thesis there is an implementation to this global platform, composed by two architectures (Fig. 2). Each one of them is oriented to solve separately, but in a collaborative manner when required, depending on the kind of user, the problems exposed on previous paragraphs, being able to obtain web applications accessible with AA level for people with severe hearing incapacity through "Sign Writing".

The first one solves the accessibility problem described in the third paragraph. In order to do that, an Accessibility adaptor is created which, with the use of templates allows the creation of interfaces which at the moment are "drawn" with javascript in the client, on the server. With this, the costs of building, or re-building, web applications accessible to AA level, according to the WAI accessibility standards and the expounded on the LSSI and the LISI are drastically cut down [3].
Rubén González Crespo et al. / Middleware architectures to adapt online contents for achieving success in changing environments using emerging techniques

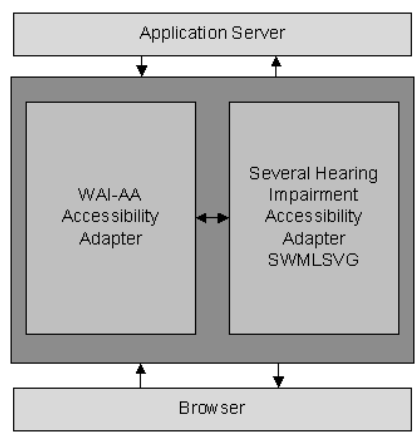

Fig. 2. Specific architecture overview.

Finally, the second one contributes a solution to allow that any website may become accessible to any person with a hearing discapacity, through a mechanism independent from any trend or regulation, as these do not exist at this time. This problem is the subject of the second paragraph. To resolve it, a framed language, SWMLSVG, has been developed [4], that allows to specify, through XML, the sign language in written mode, already known as "Sign Writing" [5], so it may become, through vectorial graphics, a new language to be used so that any web application can be transformed from spoken language to signed language.

\section{References}

[1] R. González Crespo et al., Improving cognitive load on students with disabilities through software aids, in: Social Development and High Technology Industries: Strategies and Applications, 2012, pp. 163-175.

[2] R. González Crespo et al., Un acercamiento para lograr la inmersión, en la sociedad de la información a personas con algún tipo de discapacidad: el caso de la discapacidad severa auditiva, in: Sociedad y Utopía, 2012, pp. 109-131.

[3] R. González Crespo et al., La web 3.0 al Servicio de las personas discapacitadas auditivas mediante las pautas de accesibilidad 2.0, in: Sociedad y Utopía, 2010, pp. 153-172.

[4] R. González Crespo et al., Intelligent streaming server for non-accessible contents stored on web servers to disabled people. Signwriting case, in: Advances in Soft Computing, 2008, pp. 512-520.

[5] R. González Crespo et al., SignWrting and SWML: Sign language processing, in: Sisoft, 2006, pp. 523-532. 